\title{
Factors Associated with Poor Self-rated Health in Machhapuchhre Rural Municipality of Kaski District, Nepal: A Cross-sectional Survey
}

\author{
Sharma $\mathbf{B}^{1^{*}}$, Wagle $\mathbf{S}^{3}$, Shrestha $\mathbf{N}^{1}$, Bhatt $\mathbf{M P}^{2}$, Tiwari $\mathbf{B R}^{3}$ \\ 'Department of Community Medicine, ${ }^{2}$ Department of Biochemistry, \\ Gandaki Medical College \& Teaching Hospital, Pokhara, Nepal \\ ${ }^{3}$ School of Health and Allied Sciences, Pokhara University, Pokhara, Nepal
}

\section{Keywords}

Happiness level, Health behaviors, Self-rated health, Perceived body weight.

\section{Corresponding author}

*Dr. Bimala Sharma

Associate Professor,

Department of Community Medicine,

Gandaki Medical College \& Teaching

Hospital, Pokhara, Nepal

Email: bimalasharma@gmail.com

\begin{abstract}
Introduction: Self-rated health reflects respondents' overall perceptions of their general health status. It is a simple and reliable measure of general health status of the population.
\end{abstract}

Objective: The objective of the study was to assess prevalence and associated factors of poor self-rated health among adult population in Machhapuchhre Rural Municipality of Kaski District, Nepal.

\begin{abstract}
Methods: A cross-sectional household survey was conducted among adult population at Machhapuchhre Rural Municipality. A structured questionnaire was used for the face to face interview. Household survey was conducted in July 2018. Self-rated health was measured by using a single question such as 'In general, how would you rate your health?' Responses were arranged along a five-point Likert-type scale: 'excellent', 'good', 'fair', 'poor' and very poor. The outcome variable was dichotomized as 'good' (excellent, good or fair) or 'poor' (poor or very poor). Chi-square test and multiple logistic regression analysis were performed; and odds ratios with corresponding 95\% confidence intervals for poor self-rated health were presented.
\end{abstract}

Results: Of total respondents, $13.2 \%$ respondents reported that they perceived their health as poor. Of the total, $14.3 \%$ respondents stated themselves as overweight and $8.8 \%$ mentioned they were unhappy. The study found that illiterate respondents, respondents with smoking habit and the individuals with poor psychological conditions were more likely to perceive their health as poor. Illiteracy, current smoking, perceived overweight, unhappiness, suicidal ideation and having depressed feeling were significant factors associated with poor self-rated health in the study.

Conclusion: Education, health behavior and psychosocial health variables has important influences on self-rated health.

\section{INTRODUCTION}

Self-rated health (SRH), also known as self-perceived health reflects respondents' overall perceptions of their general health status. SRH is a simple and reliable measure of general health ${ }^{1,2}$. It is typically obtained by a simple question such as "How is your health status?" or "How do you perceive your health situation?" SRH 
predicts morbidity patterns, future health status, health service utilization and quality of life ${ }^{3-5}$. It is a widely used health status indicator which has been shown to be a good predictor of objective health outcomes, including mortality ${ }^{6-8}$. Previous study states that poor SRH is a strong predictor of subsequent mortality in all subgroups studied, and that SRH therefore may be a useful outcome measure9 It is regarded as an inclusive and popular measure in health surveys and clinical studies ${ }^{1}$.

Identifying factors associated with SRH in a specific context has public health implication because it helps to better address specific characteristics of the population through public health policies and more targeted interventions. Several socio-demographic, socioeconomic, health behaviors, health condition and psychosocial factors are found to be associated with self-perceived health in different populations ${ }^{6,10-12}$. After controlling for age, sex and region, all socio-demographic factors were related to $\mathrm{SRH}^{6}$. Being a non-smoker was associated with more positive SRH levels across all groups across the adult life course ${ }^{11}$. Perceived body weight was also found to be associated with SRH in a previous study ${ }^{13,14}$. Poor SRH and unhappiness were found highly positively correlated within individuals; and communities that were healthier tend to be happier in a study among adults in USA ${ }^{15}$.

SRH can be a good screening tool for general health assessment, especially in poor countries where medical facilities for examining risk factors are not widely available and accessible to the general public. It is that SRH may be a proxy method to assess the health status of a population because of its simplicity and its wellestablished links with different health indicators in various studies ${ }^{12}$. It is found that very few studies have been conducted on SRH health among general population in Nepal. Understanding on how the people in rural area perceive their own health and which factors influence the perceived health status has meaningful implication in the study area.

Thus, the objective of the study was to assess the prevalence and associated socio-demographic, behavioral and psychological factors of poor SRH among adult population in Machhapuchhre Rural Municipality of Kaski District.

\section{METHODS}

\section{Study design}

Rivan is located at latitude of $28^{\circ} 30^{\prime} \mathrm{N}-28^{\circ} 33^{\prime} \mathrm{N}$ and longitude of $83^{\circ} 87^{\prime} \mathrm{E}-83^{\circ} 89^{\prime} \mathrm{E}$, which is at a distance of about $19.4 \mathrm{~km}$ from Prithivi Chowk, Pokhara. It has a total of 395 households and population of 1,563 according to the Ward office. A cross-sectional study was conducted among adult population in Rivan using household survey. The information for the study was collected as part of community health diagnosis program. Household survey was conducted in July 2018.

\section{Sampling method}

Out of the total nine wards of Machhapuchhre Rural Municipality/ Machhapuchhre Gau Palika, Rivan, ward number five was randomly selected for the study. Census method was applied to collect the required information from the ward. The total listed households in the ward were 395 according to the ward office profile. However, during the information collection period, the respondents only in 183 households were present. One household was excluded from the study as the respondent of the household did not show willingness to participate in the survey. A large number of households were found empty during home visit as they had migrated to other areas. A total of 182 households were surveyed for the study and included in the analysis.

\section{Information collection method}

A structured questionnaire was used for the face to face interview. The information was collected by three trained enumerators at the field. They were the students of Bachelor of Public Health Program (BPH). They were trained on the technique of interview and taking consent from the respondents, objective of the study and type of questions. The questions were prepared and asked in Nepali language. The enumerators visited all households of the ward with the structured questionnaires to conduct the face to face interview. The households where eligible respondents were not available for two consecutive visits were left. The eligible respondents were heads of the households or persons above 18 years who could provide necessary information.

\section{Measurement of variables}

The dependent variable was SRH. It was defined by the question that 'In general, how would you rate your health?' Responses were measured on a five-point Likert-type scale as 'excellent', 'good', 'neither good nor bad/fair, 'poor' and 'very poor', as it was measured in the survey by WHO (2002) and others ${ }^{6,16}$. Responses were dichotomized as 
'good' (excellent, good or fair) versus 'poor' health (poor or very poor) as it was done by Supiyev and his colleagues in their study ${ }^{6}$.

To assess the current smoking status, "Do you smoke at present?' was asked to the respondents. Alcohol consumption status was also assessed in the same way. 'How do you feel about your body weight?' was asked to assess perceived body weight. The options 'very underweight' or 'underweight' were categorized into 'underweight', and 'slightly overweight', 'overweight' or 'very overweight' were categorized into 'overweight'. 'How do you feel about your life?' was asked to assess life happiness. Responses of 'very happy', 'happy' or 'a bit happy' were categorized as 'happy' and 'a bit sad', 'sad' or 'very sad' were categorized as 'unhappy'."During the past 12 months, did you ever seriously consider attempting suicide?" was asked to assess the suicidal ideation. Similarly, suicide plan was measured by the following question, "During the last 12 months, have you made any plan of how you would try to kill yourself?" "In the last 12 months, have you had depressed feeling such as: feel yourself with little interest, sad, problems with sleep, tired without reason, distracted, or with little appetite during two continuous weeks?" was asked to measured depressed feeling.

\section{Data analysis}

The sample data were entered and analyzed using SPSS for Windows, Version 24. The $\chi 2$ test was applied to assess any associations between independent variables and SRH at a 5\% level of significance. All significant variables in the bivariate analysis were then entered into a multivariate logistic regression analysis. Unadjusted odds ratios (ORs) and adjusted odds ratios (AORs) with 95\% confidence intervals (CIs) were computed to determine the effect sizes of the independent variables on SRH. A Hosmer-Lemeshow test was applied to determine model's goodness-of-fit.

\section{Ethical consideration}

Approval was taken from the Institutional Ethical Committee of Gandaki Medical College. Approval was also taken from the Machhapuchhre Rural Municipality/ Machhapuchhre Gau Palika for the study. Informed consent was taken from all respondents before the interview. The objective of the study was made clear to them before interview. They were not forced to participate or continue the interview. Confidentiality of the information was ensured.

\section{RESULTS}

Of the total respondents, $69.8 \%$ were females and $37.9 \%$ were in the age group of 30 to 49 years. Of the total respondents, $25.8 \%$ respondents were illiterate. Regarding the marital status, $85.7 \%$ respondents were married and $74.4 \%$ were involved in agriculture. Of the total, $18 \%$ smoke and $13 \%$ drank alcohol currently. Of the total, $32.4 \%$ respondents had monthly income more than Rs. 25,000 , and $36.8 \%$ were Brahmin/ Chhetri in the study. Of the total respondents, $13.2 \%$ reported that they perceived their health condition as poor or very poor. Similarly, $14.3 \%$ respondents stated they were overweight and $8.8 \%$ reported that they were unhappy or very unhappy.

Table 1: Characteristics of the study population

\begin{tabular}{|c|c|c|}
\hline Variables & Number & Percent \\
\hline \multicolumn{3}{|l|}{ Sex } \\
\hline Male & 55 & $30.2 \%$ \\
\hline Female & 127 & $69.8 \%$ \\
\hline \multicolumn{3}{|c|}{ Age group ( in years) } \\
\hline $18-29$ & 57 & $31.3 \%$ \\
\hline $30-49$ & 69 & $37.9 \%$ \\
\hline $50-65$ & 56 & $30.8 \%$ \\
\hline \multicolumn{3}{|l|}{ Education status } \\
\hline Illiterate & 47 & $25.8 \%$ \\
\hline Literate & 135 & $74.2 \%$ \\
\hline \multicolumn{3}{|l|}{ Marital status } \\
\hline Married & 156 & $85.7 \%$ \\
\hline Others & 26 & $14.3 \%$ \\
\hline \multicolumn{3}{|c|}{ Monthly income (in Nepali Rupees) } \\
\hline$<15000$ & 66 & $36.3 \%$ \\
\hline 15000 to 25000 & 57 & $31.3 \%$ \\
\hline$>25000$ & 59 & $32.4 \%$ \\
\hline \multicolumn{3}{|l|}{ Ethnicity } \\
\hline Brahmin/ Chhetri & 67 & $36.8 \%$ \\
\hline Gurung/ Magar & 62 & $34.15 \%$ \\
\hline Disadvantage caste & 53 & $29.1 \%$ \\
\hline \multicolumn{3}{|l|}{ Occupation } \\
\hline Agriculture & 134 & $74.4 \%$ \\
\hline Others & 46 & $25.6 \%$ \\
\hline \multicolumn{3}{|l|}{ Smoking } \\
\hline Yes & 33 & $18.1 \%$ \\
\hline No & 149 & $81.9 \%$ \\
\hline \multicolumn{3}{|l|}{ Alcohol use } \\
\hline Yes & 24 & $13.2 \%$ \\
\hline No & 158 & $86.8 \%$ \\
\hline Tobacco use & & \\
\hline
\end{tabular}




$\begin{array}{lcc}\text { Yes } & 30 & 16.5 \% \\ \text { No } & 152 & 83.5 \% \\ \text { Self-rated health } & & \\ \text { Excellent/good/ fair } & 158 & 86.8 \% \\ \text { Poor/very poor } & 24 & 13.2 \% \\ \text { Perceived body weight } & & \\ \text { Underweight/ normal } & 156 & 85.7 \% \\ \text { Overweight } & 26 & 14.3 \% \\ \text { Self-rated happiness } & 166 & \\ \text { Happy } & 16 & 91.2 \% \\ \text { Unhappy } & & 8.8 \%\end{array}$

Table 2 shows bivariate analysis of the independent variables with SRH. Statistically, we did not find any significant association of sex, age group, marital status, and occupation with SRH. However, it shows that lower the education, higher the poor SRH; there was a significant association between education and SRH among the adult population in the study area. In addition, there was a statistically significant relationship between current smoking and poor SRH among the study population.

Table 2: Association of socio-demographic factors with self- rated health

\begin{tabular}{|c|c|c|c|c|}
\hline \multirow[t]{2}{*}{ Factors } & \multicolumn{2}{|c|}{ Poor self -rated health } & \multirow[t]{2}{*}{ Chi-square value } & \multirow[t]{2}{*}{$P$ value } \\
\hline & No & Yes & & \\
\hline \multicolumn{5}{|l|}{ Sex } \\
\hline Males & $47(85.5)$ & $8(14.5)$ & 0.127 & 0.721 \\
\hline Females & $111(87.4)$ & $16(12.6)$ & & \\
\hline \multicolumn{5}{|l|}{ Age group (in years) } \\
\hline $18-29$ & $53(93.0)$ & $4(7.0)$ & 5.371 & 0.068 \\
\hline $30-49$ & 61(88.4) & $8(11.6)$ & & \\
\hline $50-65$ & $44(78.6)$ & $12(21.4)$ & & \\
\hline \multicolumn{5}{|l|}{ Educational level } \\
\hline Illiterate & $35(74.5)$ & $12(25.5)$ & 8.435 & 0.004 \\
\hline Literate & 123 (91.1) & $12(8.9)$ & & \\
\hline \multicolumn{5}{|l|}{ Marital status } \\
\hline Married & 137 (87.8) & $19(12.2)$ & 0.968 & 0.325 \\
\hline Others & $21(80.8)$ & $5(19.2)$ & & \\
\hline \multicolumn{5}{|l|}{ Ethnicity } \\
\hline Brahmin/Chhetri & $61(91.0)$ & $6(9.0)$ & 5.85 & 0.054 \\
\hline Gurung/Magar & $56(90.3)$ & $6(9.7)$ & & \\
\hline Disadvantage caste & $41(77.4)$ & $12(22.6)$ & & \\
\hline \multicolumn{5}{|l|}{ Smoking } \\
\hline Yes & $24(72.7)$ & $9(27.3)$ & 6.98 & 0.008 \\
\hline No & $134(89.9)$ & $15(10.1)$ & & \\
\hline \multicolumn{5}{|l|}{ Alcohol use } \\
\hline Yes & $18(75.0)$ & $6(25.0)$ & 3.370 & 0.066 \\
\hline No & 140 (88.6) & 18 (11.4) & & \\
\hline
\end{tabular}

Table 3 shows bivariate analysis of psychological health variables with SRH. A significant association was found between SRH and perceived body weight among the study population. In the same way, there was a significant association between SRH and happiness level among the respondents. Suicidal ideation, suicide plan and having depressed feeling also had significant association with SRH. It shows that poor psychological health had negative impact on SRH.

Table 3: Association of psychological health status with self-rated health

\begin{tabular}{|c|c|c|c|c|}
\hline \multirow[t]{2}{*}{ Factors } & \multicolumn{2}{|c|}{ Poor self -rated health } & \multirow[t]{2}{*}{ Chi-square value } & \multirow[t]{2}{*}{ P value } \\
\hline & No & yes & & \\
\hline \multicolumn{5}{|c|}{ Perceived body weight } \\
\hline Underweight & $17(89.5)$ & $2(10.5)$ & 12.183 & 0.002 \\
\hline Normal & $124(90.5)$ & $13(9.5)$ & & \\
\hline Overweight & $17(65.4)$ & $9(34.6)$ & & \\
\hline \multicolumn{5}{|c|}{ Self-rated happiness } \\
\hline Happy & $152(91.6)$ & $14(8.4)$ & 37.264 & 0.000 \\
\hline Unhappy & $6(37.5)$ & $10(62.5)$ & & \\
\hline \multicolumn{5}{|c|}{ Suicidal ideation } \\
\hline Yes & $3(50.0)$ & $3(50.0)$ & 7.345 & 0.007 \\
\hline No & 155 (88.1) & $21(11.9)$ & & \\
\hline \multicolumn{5}{|l|}{ Suicide plan } \\
\hline Yes & $3(42.9)$ & $4(57.1)$ & 12.287 & 0.000 \\
\hline No & $155(88.6)$ & $20(11.4)$ & & \\
\hline \multicolumn{5}{|c|}{ Feeling depressed } \\
\hline Yes & $20(66.7)$ & $10(33.3)$ & 12.736 & 0.000 \\
\hline No & 138 (90.8) & $14(9.2)$ & & \\
\hline
\end{tabular}

Illiterate respondents were 3.5 times more likely to have poor SRH as compared to literate respondents in the unadjusted analysis. However, education was not found to have any significant effect on the adjusted analysis. Smoking was found to be a significant factor in both unadjusted and adjusted analysis. Current smoker were 3.8 times more likely to feel poor SRH as compared to non-smokers in the adjusted analysis. The respondents who were unhappy had increased likelihood of perceiving their health status as poor while compared to those who expressed themselves as happy. Unhappy respondents were 9.6 times more likely to report poor SRH in the adjusted analysis. Suicidal ideation had significant association with SRH in unadjusted analysis. Respondents who had depressed feeling in last 12 months were also more likely to express poor SRH in the unadjusted analysis. Likelihood of poor SRH was fivefold higher among those who perceived themselves as overweight as compared to 
those who perceived themselves as normal (AOR, 5.4; 95\% CI, 1.6- 18.6) (Table 4).

The adjusted analysis showed that $36.4 \%$ variance in the SRH was predicted by the factors included in the analysis. The model was fit for the factors included as Hosmer \& Lemeshow Test was not significant ( $p>0.05)$.

Table 4: Logistic regression analysis of independent variables with self-rated health

\begin{tabular}{|c|c|c|c|c|}
\hline \multirow[t]{2}{*}{ Factors } & \multicolumn{2}{|c|}{ Unadjusted analysis } & \multicolumn{2}{|c|}{ Adjusted analysis } \\
\hline & OR $(95 \% \mathrm{CI})$ & $P$ value & $\mathrm{A0R}(95 \% \mathrm{Cl})$ & $P$ value \\
\hline $\begin{array}{l}\text { Education (Illiterate vs. } \\
\text { literate ) }\end{array}$ & $\begin{array}{l}3.51(1.4 \\
-8.5)\end{array}$ & 0.005 & $\begin{array}{c}1.5(0.48- \\
4.7)\end{array}$ & 0.472 \\
\hline Current smoking(Yes vs. No) & $\begin{array}{c}3.35(1.3 \\
-8.5)\end{array}$ & 0.011 & $\begin{array}{l}3.8(1.2- \\
12.4)\end{array}$ & 0.023 \\
\hline $\begin{array}{l}\text { Self-ratedhappiness } \\
\text { (Unhappy vs. Happy) }\end{array}$ & $\begin{array}{l}18.09 \\
(5.7- \\
57.1)\end{array}$ & 0.000 & $\begin{array}{l}9.6(2.0- \\
44.5)\end{array}$ & 0.004 \\
\hline $\begin{array}{l}\text { Suicidal ideation (Yes } \\
\text { vs. No) }\end{array}$ & $\begin{array}{l}7.38(1.4 \\
-38.9)\end{array}$ & 0.019 & $\begin{array}{c}1.9(0.17- \\
22.3)\end{array}$ & 0.586 \\
\hline $\begin{array}{l}\text { Feeling depressed } \\
\text { (Yes vs. No) }\end{array}$ & $\begin{array}{c}4.9(1.9- \\
12.5)\end{array}$ & 0.001 & $\begin{array}{l}2.12(0.60 \\
-7.5)\end{array}$ & 0.243 \\
\hline $\begin{array}{l}\text { Perceived body weight } \\
\text { Normal vs. overweight }\end{array}$ & $\begin{array}{l}1.1(0.23 \\
-5.40)\end{array}$ & 0.886 & $\begin{array}{c}0.62(0.09 \\
-4.0)\end{array}$ & 0.620 \\
\hline Thin vs. overweight & $\begin{array}{c}5.0(1.8- \\
13.5)\end{array}$ & 0.001 & $\begin{array}{c}5.4(1.6- \\
18.6)\end{array}$ & 0.007 \\
\hline$P$ value (Hosmer \& Lemeshow Test & & & 0.977 & \\
\hline Nagelkerke R Square & & & 0.364 & \\
\hline
\end{tabular}

ORs: odds ratios, AOR: adjusted odds ratios, $\mathrm{CI}$ : confidence interval

\section{DISCUSSION}

The prevalence of poor SRH was found to be $13 \%$ in the study area. The study revealed that poor psychological health had negative impact on SRH; and current smoking also increased the likelihood of poor SRH. A study conducted in Kailali District had found that 19.7\% perceived their health as poor which is higher than the figure found in our study ${ }^{12}$. However, the difference was due to the difference in the measurement scale of SRH; the mentioned study included only 'excellent health' and 'good health' into the category of good. In contrast to the study, the prevalence of poor/very poor self-rated health was $5.3 \%$ in Kazakhstan ${ }^{6}$.

Our study found that current smoking increased the likelihood of poor SRH in the study area. The finding is consistent with previous finding that shows being a nonsmoker was associated with more positive SRH levels across the adult life course ${ }^{11}$. Another study conducted in Kailali district also found that non-smoking status and higher level of happiness were associated with better selfperceived health ${ }^{12}$. It indicates that unhealthy behavior like smoking might be associated with morbidities that cause poor perceived health status.

In the study, perceived overweight was significantly increased the likelihood of perceiving themselves as poor health status. Similar results were observed in other previous study ${ }^{13}$. The obese adults rate their health more negatively than non-obese when using overall SRH. The study conducted by Altman provided indirect evidence that the relationship between obesity and SRH is socially patterned according to exposure to information about obesity and the availability of resources ${ }^{13}$. In contrast to our study, a study conducted among school going adolescents in South America had found no significant association between perceived body weight and $\mathrm{SRH}^{14}$. The difference might be due to difference in the study population and the study area.

Health and happiness share important similarities with respect to their determinants. Disease itself might be a reason of unhappiness. Similar to the study, a study by Siahpush et al (2008) found that happiness was positively associated with excellent, very good, or good health ${ }^{17}$. Poor SRH and unhappiness were found highly positively correlated within individuals; and communities that were healthier tend to be happier in a study among adult in $U_{S A}{ }^{15}$. Life satisfaction significantly predicted SRH in other previous studies too ${ }^{18,19}$. However, a bidirectional relationship between SRH and life satisfaction could be present, each predisposing the other ${ }^{20}$. These results suggest that SRH is greatly affected by psychological factors and health behaviors than the socio-demographic factors.

\section{CONCLUSION}

Prevalence of poor SRH was found relatively high in the study area i.e. $13.2 \%$. The study found that current smokers and respondents with poor psychological conditions were more likely to perceive their health as poor. Illiteracy, current smoking status, perceived overweight, unhappiness, having depressed feeling, suicidal ideation were significantly associated with poor SRH. Psychosocial health variables have important influences on SRH. 


\section{Acknowledgements}

The authors express their special thanks to the study participants and everyone who helped directly and indirectly to make this survey possible. We would like to express our sincere thanks to Professor Ishwari Sharma Paudel, Head of Department, Community Medicine Department, Gandaki Medical College for his kind support and encouragement. We would also like to sincerely acknowledge Mr Thaneshor Paneru, Mr Sudeep Khanal and Mr Sandesh Paudel, Bachelor of Public Health (BPH) students of Gandaki Medical College, who helped for information collection and data entry.

\section{REFERENCES}

1. Bombak AE. Self-rated health and public health: A critical perspective. Front Public Health. 2013; 1: 1518.

2. Heistaro S, Jousilahti P, Lahelma E, et al. Self-rated health and mortality: A long term prospective study in Eastern Finland. J Epidemiol Community Health. 2001; 55: 227-32.

3. Manor O, Matthews S, Power C. Self-rated health and limiting longstanding illness: Inter-relationships with morbidity in early adulthood. Int J Epidemiol. 2001; 30: 600-7.

4. Bath PA. Self-rated health as a risk factor for prescribed drug use and future health and social service use in older people. J Gerontol A Biol Sci Med Sci. 1999; 54: M565-70.

5. Abdulrahim S, El Asmar K. Is self-rated health a valid measure to use in social inequities and health research? Evidence from the PAPFAM women's data in six Arab countries. Int J Equity Health. 2012; 11: 53.

6. Supiyev A, Nurgozhin T, Zhumadilov Z, Sharman A, Marmot M, Bobak M. Levels and distribution of selfrated health in the Kazakh population: Results from the Kazakhstan household health survey 2012. BMC Public Health. 2014; 14(1): 768.

7. Zhao J, Yiengprugsawan V, Seubsman SA, Kelly M, Bain C, Sleigh A. Self-reported health and subsequent mortality: An analysis of 767 deaths from a large Thai cohort study. BMC Public Health. 2014; 14(1): 860.

8. Jylhä M. What is self-rated health and why does it predict mortality? Towards a unified conceptual model. Social Science \& Medicine. 2009; 69(3): 307316.

9. Burström B, Fredlund P. Self rated health: Is it as good a predictor of subsequent mortality among adults in lower as well as in higher social classes? Journal of Epidemiology \& Community Health. 2001; 55(11): 836-840.

10. Chun J, Nam S, Chung IJ, Kang H, Nho CR, Woo S. Factors associated with perceived health among Korean adolescents. Social Work in Public Health. 2014; 29(6): 528-539.

11. Sargent-Cox K, Cherbuin N, Morris L, Butterworth P, Anstey KJ. The effect of health behavior change on self-rated health across the adult life course: A longitudinal cohort study. Preventive Medicine. 2014; 58: 75-80.

12. Freidoony L, Chhabi R, Kim CS, Park MB, Kim CB. The components of self-perceived health in the Kailali District of Nepal: a cross-sectional survey. Int J Envir Research Public Health. 2015; 12(3): 3215-3231.

13. Altman CE, Van Hook J, Hillemeier M. What does selfrated health mean? Changes and variations in the association of obesity with objective and subjective components of self-rated health. Journal of Health and Social Behavior. 2016; 57(1): 39-58.

14. Sharma B, Nam EW, Kim D, Yoon YM, Kim Y, Kim HY. Role of gender, family, lifestyle and psychological factors in self-rated health among urban adolescents in Peru: A school-based cross-sectional survey. BMJ Open. 2016; 6(2): e010149.

15. Subramanian SV, Kim D, Kawachi I. Covariation in the socioeconomic determinants of self rated health and happiness: A multivariate multilevel analysis of individuals and communities in the USA. Journal of Epidemiology \& Community Health. 2005; 59(8): 664669.

16. World Health Survey 2002. Individual questionnaire. Geneva: World Health Organization; 2002. 
Original Article | Journal of Gandaki Medical College-Nepal

17. Siahpush M, Spittal M, Singh GK. Happiness and life satisfaction prospectively predict self-rated health, physical health, and the presence of limiting, longterm health conditions. American Journal of Health Promotion. 2008; 23(1): 18-26.

18. Piko BF. Self-perceived health among adolescents: the role of gender and psychosocial factors. European Journal of Pediatrics. 2007; 166(7): 701-708.

19. Meireles AL, Xavier CC, Proietti FA, Caiaffa WT. Influence of individual and socio-environmental factors on self-rated health in adolescents. Revista Brasileira de Epidemiologia. 2015; 18: 538-551.

20. Zullig KJ, Valois RF, Huebner ES, Drane JW. Adolescent health-related quality of life and perceived satisfaction with life. Quality of life Research. 2005; 14(6): 15731584. 